\title{
ASO Visual Abstract: Access Denied-Inequities in Clinical Trial Enrollment for Pancreatic Cancer
}

\author{
Mariam F. Eskander, MD, MPH ${ }^{1,2}$, Lindsay Gil, MD ${ }^{1}$, Eliza W. Beal, MD ${ }^{1}$, Yaming Li, MS ${ }^{1}$, \\ Ahmad Hamad, MD ${ }^{1}$, Bridget Oppong, MD ${ }^{1}$, Samilia Obeng-Gyasi, MD, MPH ${ }^{1}$, and Allan Tsung, MD ${ }^{1}$ \\ ${ }^{1}$ Division of Surgical Oncology, The Arthur G. James Cancer Hospital and Solove Research Institute at the Ohio State \\ University Wexner Medical Center, Columbus, OH; ${ }^{2}$ Rutgers Cancer Institute of New Jersey, New Brunswick, NJ
}

Age, race, insurance, and geography are barriers to clinical trial enrollment in a national cohort of pancreatic cancer patients. While more patients enrolled in trials between 2004 and 2016, black patients and Medicaid patients remain underrepresented (https://doi.org/10.1245/ s10434-021-10868-4).

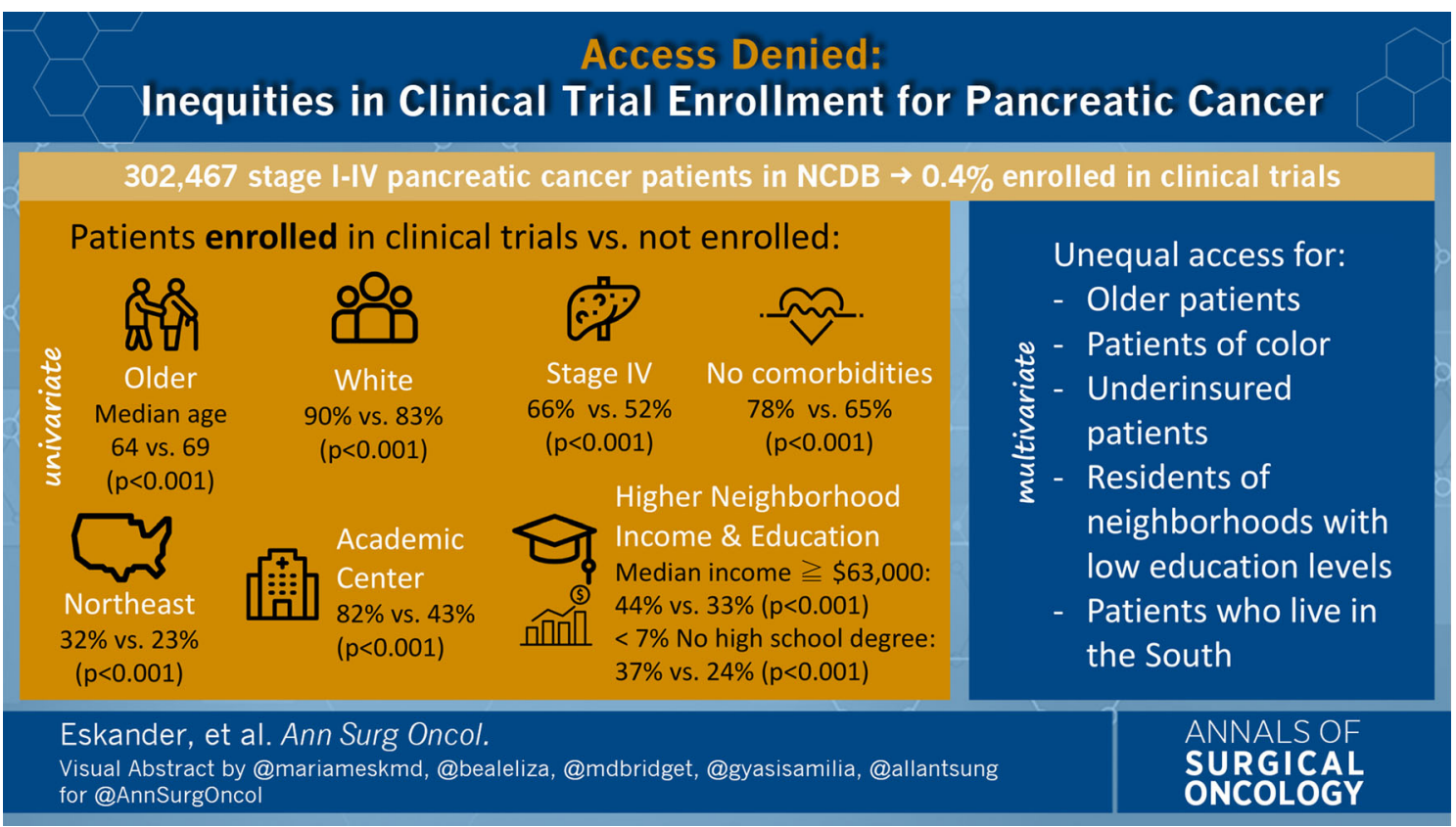

Poster presentation at the 2021 Society for Surgical Oncology International Conference on Surgical Cancer Care.

(C) Society of Surgical Oncology 2021

Published Online: 30 October 2021

A. Tsung, MD

e-mail: allan.tsung@osumc.edu
FUNDING None.

Publisher's Note Springer Nature remains neutral with regard to jurisdictional claims in published maps and institutional affiliations. 